JURNAL TE[KNOSAINS

VOLUME 1

No. 2, 22 Juni 2012

Halaman 71-143

\title{
PEMANFAATAN CITRA IKONOS UNTUK IDENTIFIKASI OBJEK PAJAK BUMI DAN BANGUNAN
}

\author{
Wiji Lestari \\ Pengelolaan Infrastruktur dan Pembangunan Masyarakat \\ Sekolah Pascasarjana Universitas Gajah MadaYogyakarta \\ Email: awanbiru2512@yahoo.com
}

\begin{abstract}
Ikonos satellite image is an image that has a high spatial resolution with pixel accuracy of one meter for panchromatic and four-meter multispectral. Spesifkasi IKONOS imagery provides the ability to record an object one meter. Therefore the use of Ikonos imagery to identify objects and buildings Land Tax (PBB) is dimungkinkan.Untuk determine the ability of Ikonos imagery in the identification of objects Land and Building Tax (PBB) conducted research that aims to determine the accuracy of the interpretation of Ikonos imagery for identification of objects UN, UN to map objects based on Ikonos imagery interpretation, field survey and evaluate the results of Block Maps uses map image interpretation Ikonos.Penelitian geografi.Pengumpulan using descriptive methods of data is done through the interpretation of Ikonos imagery, field tests, interviews and documentation. Data analysis is the analysis of the level of image interpretation, analysis and map overlay analysis. The results showed that the level of interpretation of Ikonos imagery for identification of objects and the United Nations is $89.54 \%$ commission error is $10.46 \%$. Results from a block map using Ikonos imagery interpretation of evaluation results have not yet registered 269 objects in the map of Block UN tax. Can be concluded that the Ikonos imagery can be used as the primary data source for identification of objects.
\end{abstract}

Key words: Ikonos image, image interpretation, object identification, remote sensing, object of property tax.

\begin{abstract}
ABSTRAK
Citra Ikonos adalah citra satelit yang memiliki resolusi spasial tinggi dengan ketelitian piksel satu meter untuk pankromatik dan empat meter untuk multispektral. Spesifkasi ini memberikan citra ikonos kemampuan merekam obyek sebesar satu meter. Oleh karena itu, penggunaan citra Ikonos untuk mengidentifikasi obyek Pajak Bumi dan bangunan (PBB) sangat dimungkinkan.Untuk mengetahui kemampuan citra Ikonos dalam identifikasi objek Pajak Bumi dan Bangunan (PBB) dilakukan penelitian yang bertujuan untuk mengetahui tingkat ketelitian interpretasi citra Ikonos untuk identifikasi objek PBB, memetakan obyek PBB berdasarkan hasil interpretasi citra Ikonos, dan mengevaluasi Peta Blok dari hasil survey lapangan menggunakan peta hasil interpretasi citra Ikonos. Penelitian ini menggunakan metode deskriptif geografi. Pengumpulan data dilakukan melalui interpretasi citra Ikonos, uji lapangan, wawancara, dan dokumentasi. Analisis data yang dilakukan adalah analisis tingkat interpretasi citra, analisis peta, dan analisis overlay. Hasil penelitian memperlihatkan bahwa tingkat interpretasi citra Ikonos untuk identifikasi obyek PBB adalah 89,54\% dan kesalahan komisi adalah 10,46\%. Hasil evaluasi
\end{abstract}


peta Blok menggunakan hasil intrepretasi citra Ikonos terdapat 269 obyek pajak belum terdaftar dalam peta Blok PBB. Jadi dapat disimpulkan bahwa citra Ikonos dapat digunakan sebagai sumber data utama untuk identifikasi objek.

Kata Kunci: citra ikonos, interpretasi citra, identifikasi obyek, penginderaan jauh, obyek Pajak Bumi dan Bangunan.

\section{PENGANTAR}

Penginderaan jauh adalah ilmu dan seni untuk memperoleh informasi tentang objek, daerah atau gejala dengan jalan menganalisis data yang diperoleh dengan menggunakan alat tanpa kontak langsung terhadap objek, daerah atau gejala yang dikaji (Lillesand dan Kiefer,1990: 5). Pengumpulan data dalam penginderaan jauh dilakukan dari jarak jauh dengan menggunakan sensor buatan. Sensor merekam tenaga yang dipantulkan atau dipancarkan oleh objek di permukaan bumi. Setelah diproses rekaman tenaga ini membuahkan data penginderaan jauh. Dengan melakukan analisis terhadap data yang terkumpul ini dapat diperoleh informasi tentang obyek, daerah, atau gejala yang dikaji.

Citra penginderaan jauh merupakan gambaran yang menyerupai wujud asli dari objek yang direkam. Identifikasi objek di lapangan melalui citra dapat dilakukan dengan intepretasi atau penafsiran citra penginderaan jauh agar dapat menilai arti pentingnya objek tersebut (Purwadhi, 2001: 22). Kualitas objek yang terekam pada citra bergantung pada resolusi citra tersebut. Resolusi adalah parameter limit atau daya pisah objek yang masih dapat dibedakan (Purwadhi, 2001:18 - 19).

Ikonos adalah satelit milik Space Imaging (USA) yang diluncurkan bulan September 1999 dan menyediakan data untuk tujuan komersial pada awal tahun 2000. Ikonos adalah satelit dengan resolusi spasial tinggi yang merekam data multispektral 4 kanal pada resolusi 4 meter dan sebuah kanal pankromatik dengan resolusi satu meter. Ini berarti Ikonos merupakan satelit komersial pertama yang dapat membuat image beresolusi tinggi (Rovicky,2006:1). Spesifikasi ini memberikan kemampuan Citra Ikonos untuk dapat merekam obyek lebih detail dibandingkan dengan citra lain yang memiliki resolusi spasial yang lebih rendah. Karakteristik satelit ikonos diperlihatkan dalam Tabel 1.

Tabel 1.

Karakteristik Satelit Ikonos

\begin{tabular}{|c|c|}
\hline Elemen & Keterangan \\
\hline Launch Date & $\begin{array}{l}24 \text { September } 1999 \\
\text { Vandenberg Air Force Base, } \\
\text { California }\end{array}$ \\
\hline Operational Life & Over 7 Years \\
\hline Orbit & 98.1 degree, sun synchronous \\
\hline Speed on Orbit & $\begin{array}{l}7.5 \text { kilometers ( } 4.7 \text { miles) per } \\
\text { second }\end{array}$ \\
\hline $\begin{array}{l}\text { Speed Over the } \\
\text { Ground }\end{array}$ & $\begin{array}{l}6.8 \text { kilometers ( } 4.2 \text { miles) per } \\
\text { second }\end{array}$ \\
\hline $\begin{array}{l}\text { Number of } \\
\text { Revolutions Around } \\
\text { the Earth }\end{array}$ & 14.7 every 24 hours \\
\hline $\begin{array}{l}\text { Orbit Time Around } \\
\text { the Earth }\end{array}$ & 98 minutes \\
\hline Altitude & 681 kilometers (423 miles) \\
\hline Resolution & $\begin{array}{l}\text { Nadir: } 0.82 \text { meters ( } 2.7 \text { feet) } \\
\text { panchromatic } 3.2 \text { meters } \\
\text { (10.5 feet) multispectral } 26^{\circ} \\
\text { Off-Nadir } 1.0 \text { meter ( } 3.3 \text { feet) } \\
\text { panchromatic } 4.0 \text { meters ( } 13.1 \\
\text { feet) multispectral }\end{array}$ \\
\hline Image Swath & $\begin{array}{l}11.3 \text { kilometers ( } 7.0 \text { miles) at } \\
\text { nadir } \\
13.8 \text { kilometers ( } 8.6 \text { miles at } 26^{\circ} \\
\text { off-nadir) }\end{array}$ \\
\hline Equator Crossing Time & Nominally 10:30 a.m. solar time \\
\hline Revisit Time & $\begin{array}{l}\text { Approximately } 3 \text { days at 1-meter } \\
\text { resolution, } 40^{\circ} \text { latitude }\end{array}$ \\
\hline Dynamic Range & 11-bits per pixel \\
\hline Image Bands & $\begin{array}{l}\text { Panchromatic, blue, green, red, } \\
\text { near infrared }\end{array}$ \\
\hline
\end{tabular}

Sumber: Space Imaging (2003: 1)

Saat ini Direktorat Jenderal (Dirjen) Pajak telah memiliki citra satelit dari sebagian besar wilayah Indonesia, yaitu citra Ikonos. Citra Ikonos memiliki resolusi spasial tinggi dengan ketelitian piksel 1 meter untuk pankromatik dan 4 meter untuk multispektral. Resolusi spasial yang tinggi tersebut memberikan kemampuan Citra Ikonos untuk mendeteksi obyek sebesar 1 meter. Kelebihan lainnya, Citra Ikonos dapat memberikan informasi 
yang aktual sesuai dengan kondisi lapangan pada saat perekaman data. Dengan kelebihan tersebut, dimungkinkan dapat diperoleh informasi yang lebih lengkap dan terkini mengenai kondisi wilayah yang akan didata sebagai obyek pajak beserta distribusi spasialnya. Beberapa informasi yang dapat diperoleh untuk pendataan dan penilaian PBB antara lain jenis dan fungsi lahan, ukuran, letak objek pada kelas tanah, jumlah obyek pajak, dan sebagainya.

Saat ini identifikasi obyek pajak untuk pendataan pajak di Kantor Pelayanan Pajak (KPP) Kota Surakarta Kota masih menggunakan metode konvensional yaitu identifikasi langsung di lapangan. Menurut petugas pajak bahwa identifikasi dilakukan oleh pihak ketiga (outsourcing) dan kelurahan serta diawasi oleh pihak KPP. Hasil identifikasi tersebut kemudian divalidasi oleh petugas KPP. Setelah proses validasi, KPP mengeluarkan Surat Pemberitahuan Pajak Terutang (SPPT) yang akan diserahkan oleh subyek pajak melalui kantor kelurahan. Identifikasi tidak dilakukan tiap tahun, tetapi dilihat dari potensi suatu wilayah atau suatu wilayah tersebut sudah lama tidak dilakukan pemeliharaan data. Pemeliharaan data meliputi perubahan nama pemilik, alamat, luas tanah, dan letak tanah serta data tersebut disimpan dalam Smart Map PBB. Cara identifikasi tersebut melibatkan banyak sumberdaya manusia. Selain itu, memerlukan dana yang cukup besar dan waktu yang lama, apalagi jika wilayah yang didata luas dan memiliki perkembangan fisik yang cepat, sehingga banyak obyek data baru yang harus diidentifikasi.

Penelitian ini ingin menampilkan sebuah metode untuk identifikasi obyek PBB menggunakan interpretasi Citra Ikonos. Interpretasiatau penafsirancitrapenginderaan jauh merupakan kegiatan mengeksplorasi informasi dari citra dengan maksud untuk mengidentifikasi obyek yang tergambar pada citra (Purwadhi, 2001: 25). Data interpretasi citra dapat digunakan apabila memenuhi syarat uji ketelitian interpretasi. Uji ketelitian interpretasi citra dapat dilakukan dengan berbagai cara. Uji ketelitian dalam penelitian ini menggunakan tabel perhitungan matrik konfusi.Tabel perhitungan matrik konfusi merupakan derivasi dari penjumlahan omisi, komisi, dan keseluruhan ketelitian pemetaan (Short, 1982: 12). Omisi adalah jumlah kesalahan interpretasi dari objek $\mathrm{X}$ dibagi jumlah seluruh objek yang diinterpretasi. Komisi adalah jumlah objek lain yang diinterpretasikan sebagai objek $\mathrm{X}$ dibagi jumlah seluruh objek yang diinterpretasi, sedangkan ketelitian pemetaan adalah jumlah objek $X$ yang diinterpretasi benar dibagi jumlah objek $X$ yang diinterpretasi benar ditambah jumlah omisi dan komisi. Ketelitian pemetaan dihitung tiap klasifikasi objek. Keseluruhan ketelitian pemetaan dihitung dengan menjumlahkan objek X yang diinterpretasi benar dari semua klasifikasi objek dibagi dengan jumlah seluruh sampel objek. Data interpretasi citra telah memenuhi syarat apabila tingkat ketelitian interpretasi> $84 \%$, sedangkan kesalahan komisi $<20 \%$ (Sutanto,1994: 116)

Hasil interpretasi Citra Ikonos digunakan untuk memetakan obyek PBB yang digunakan untuk mengevaluasi peta Blok dari KPP. Peta Blok adalah peta yang dibuat oleh KPP yang berisi informasi tentang obyek pajak dalam areal pengelompokan bidang tanah terkecil yang digunakan sebagai petunjuk lokasi objek pajak yang unik dan permanen. Informasi obyek dalam Peta Blok diperoleh memalui survei lapangan. Evaluasi Peta Blok berdasarkan interpretasi Citra Ikonos menggunakan analisis overlay, yaitu membandingkan minimal dua layer peta dalam proyeksi dan koordinat yang sama, tetapi memiliki kandungan informasi yang berbeda. Dari perbedaan ini dicari perpotongan atau kombinasi dari obyek hasil overlay. Pada penelitian ini, perbedaan informasi yang diambil adalah informasi selisih antara jumlah objek pajak yang terdapat pada peta blok PBB dengan jumlah 
objek pajak yang berhasil di identifikasi melalui interpretasi Citra Ikonos.

\section{Kerangka Teoritik}

Penelitian yang dilakukan Santosa berjudul "Penggunaan Foto Udara Untuk Memetakan Objek Pajak Bumi dan Bangunan di Kotamadya Yogyakarta" (Santosa, 197). Metode yang digunakan yaitu pembagian wilayah, pengumpulan data, dan analisa data. Luas dihitung dengan sistem grid yaitu dengan membagi tiap blok dan tiap penggunaan lahan dalam kotak-kotak kecil dengan ukuran tertentu. Dari hasil penelitian diketahui bahwa foto udara pankromatik hitam putih skala 1:10.000 dapat digunakan untuk identifikasi objek PBB dan memetakannya. Nilai ketelitian seluruh klasifikasi sebesar 89,37\%, sedangkan jumlah objek PBB yang ada di Kotamadya Yogyakarta ditaksir sebanyak 61.464 buah.

Pramadani (2004), melakukan penelitian berjudul"Pemanfaatan Citra Satelit Ikonos dan Sistem Informasi Geografi Untuk Mengetahui Nilai Jual Objek Pajak Bumi Di Kecamatan Danurejan Kota Yogyakarta." Metode yang digunakan yaitu pengharkatan atau skoring dan pembobotan. Satuan pemetaan yang digunakan yaitu blok. Dari hasil penelitian diketahui bahwa citra Ikonos warna asli (True Color) dapat dimanfaatkan dalam identifikasi bentuk penggunaan lahan. Hasil ketelitian uji intepretasi sebesar $83,33 \%$. Berdasarkan hasil pemetaan, nilai jual bumi/lahan di daerah penelitian dibagi menjadi lima kelas menunjukkan nilai jual bumi / lahan Kelas I (sangat tinggi), Kelas II (tinggi), Kelas III (sedang), Kelas IV (rendah), dan Kelas V (sangat rendah).

Simarangkir (2005), melakukan penelitian berjudul "Pemanfaatan Citra Ikonos Dalam Kegiatan Peningkatan Potensi Penerimaan Pajak Bumi dan Bangunan (Studi Kasus: Kelurahan Sukaresi, Kecamatan Tanah Sareal, dan Kota Bogor)". Metode yang digunakan yaitu survei lapangan, intepretasi citra Ikonos, dan perbandingan hasil intepretasi dengan hasil survei lapangan. Dari hasil penelitian diketahui bahwa berdasar perbandingan hasil intepretasi citra Ikonos dengan peta blok PBB, ditemukan perbedaan pada luas bangunan yaitu 149. $696 \mathrm{~m} 2$ dan luas penggunaan lahan yaitu $209.789 \mathrm{~m} 2$.

Bambang Edhi Leksono dan Yuliana Susilowati (2008) melakukan penelitian berjudul The Accuracy Improvement of Spasial Data for Land Parcel and Buildings Taxation Objects by Using the Large Scale Ortho Image Data. Metode yang digunakan yaitu pengumpulan data lapangan, pemrosesan data, dan membandingkan posisi objek antara digitasi peta citra dengan data lapangan. Pemrosesan citra Quickbird pada penelitian ini menghasilkan RMSE pada proses rektifikasi sebesar 0,938 m untuk 10 titik GCP dan 0,876 m untuk 22 GCP, sedangkan pada proses orthorektifikasi menghasilkan RMSE 0.564 m untuk 10 GCP dan 0,541 untuk 22 GCP.

\section{Bahan dan Metode}

Lokasi yang digunakan untuk penelitian ini adalah Kecamatan Jebres, Kota Surakarta. Kecamatan Jebres dipilih sebagai tempat penelitian karena merupakan kecamatan yang mengalami pertumbuhan fisik dan sosial yang cepat, sehingga sering terjadi perubahan penggunaan lahan dan dimungkinkan terdapat penambahan obyek PBB yang bervariasi.

Dalam penelitian ini digunakan metode deskriptif geografis yaitu memaparkan analisis data secara spasial, sedangkan data yang digunakan dalam penelitian ini adalah data kualitatif. Data diperoleh melalui interpretasi citra Ikonos, kemudian dilakukan uji ketelitian interpretasi citra menggunakan perhitungan matrik konfusi. Selanjutnya, dilakukan overlay hasil interpretasi citra tersebut dengan peta blok hasil survey lapangan yang dimiliki KPP.

Populasi dalam penelitian ini meliputi seluruh tanah dan bangunan yang menjadi obyek pajak di Kecamatan Jebres, sejumlah 
1227 obyek yang terbagi dalam 18 klasifikasi obyekpajak.Sampelyangdigunakansebanyak 153 meliputi 18 klasifikasi obyek, yaitu 2 gudang, 3 tempat olahraga, 4 SPBU, 8 sekolah, 51 rumah, 4 rumah sakit, 5 pasar, 22 industri dan perkantoran, 4 tempat ibadah, 9 lahan terbuka, 4 hotel, 5 kuburan, 24 pertokoan, 3 kantor pemerintahan, 1 kolam IPAL, 1 stasiun kereta api, 1 kebun binatang, dan 2 taman kota. Pengambilan sampel dilakukan dengan cara stratified proposional random sampling dan didasarkan atas strata kelas obyek pajak yang ada pada setiap kelurahan. Sampel diambil dengan memperhatikan proporsi jumlah sampel, sehingga seluruh populasi terwakili oleh sampel yang diambil. Titik sampel yang diambil secara acak (random) didasarkan atas jumlah strata (kelas).

Data primer yang diambil dalam penelitian ini bersumber dari Citra Satelit Ikonos daerah liputan Kota Surakarta tahun 2002 dan data cek lapangan pada waktu melakukan uji ketelitian interpretasi. Data sekunder yang diperlukan dalam penelitian ini adalah koordinat titik ikat yang digunakan untuk registrasi citra, data realisasi penerimaan PBB serta Peta Blok digital Kecamatan Jebres layer bangunan, persil tanah, sungai dan jalan.

Teknik pengumpulan data dilakukan dengan interpretasi citra Ikonos, uji lapangan, dokumentasi, dan wawancara. Teknik analisis data yang digunakan dalam penelitian ini adalah analisis tingkat ketelitian interpretasi citra, yaitu analisis yang dilakukan berdasarkan uji ketelitian interpretasi menggunakan perhitungan matrik konfusi. Matrik konfusi dihitung berdasarkan hasil interpretasi citra. Matrik konfusi memuat perhitungan ketelitian masing-masing klasifikasi obyek dan interpretasi keseluruhan. Selain itu, matrik tersebut memuat perhitungan omisi dan komisi yaitu perhitungan kesalahan interpretasi, sehingga uji ketelitian tersebut tidak termasuk pengukuran tunggal dan merupakan prosedur uji ketelitian yang sangat valid. Uji ketelitian interpretasi citra dilakukan dengan melakukan cek lapangan dengan sampel objek yang sudah ditentukan. Perhitungan pengujian berdasarkan kesesuaian hasil interpretasi dengan kondisi lapangan, sehingga kesalahan interpretasi dapat diketahui. Melalui uji ketelitian ini diketahui tingkat akurasi interpretasi citra Ikonos.Teknik analisis kedua adalah analisis pemetaan obyek PBB. Analisis ini didasarkan pada peta hasil interpretasi citra Ikonos yang telah diketahui tingkat ketelitiannya.Teknik analisis ketiga adalah analisis overlay. Overlay adalah analisis spasial dengan menggunakan minimal 2 layer dalam posisis yang sama dengan kandungan informasi yang berbeda. Dari perbedaan ini dicari perpotongan obyek atau kombinasi obyek hasil overlay. Analisi ini digunakan untuk mengevaluasi peta Blok PBB.

\section{PEMBAHASAN}

Pengolahan data dalam penelitian ini dimulai dari kegiatan interpretasi citra. Dalam penelitian ini digunakan interpretasi secara visual menggunakan delapan unsur interpretasi citra, yaitu rona atau warna, bentuk, ukuran, tekstur, pola, bayangan, situs, dan asosiasi. Identifikasi obyek pajak dibagi menjadi dua bagian, untuk memudahkan analisis, yaitu obyek non pajak dan obyek wajib pajak. Dalam penelitian ini obyek non pajak yang berhasil diidentifikasi adalah sekolah, kuburan, rumahsakit pemerintah, kantor pemerintah, lapangan, tempat ibadah, kolam IPAL, dan taman kota, sedangkan obyek wajib pajak yang berhasil diidentifikasi antara lain rumah, pabrik atau perkantoran, pasar, tempat olah raga, hotel, kebun binatang yang dikelola swasta, gudang, rumah sakit swasta, stasiun kereta api, dan SPBU.

Ketelitian hasil interpretasi citra diketahui dengan cara dilakukan cek lapangan dengan mengambil sampel beberapa obyek penelitian. Pengambilan sampel uji ketelitian interpretasi didasarkan atas unit kelurahan. Pada penelitian ini diambil sampel sebanyak 153. Sampel yang diambil adalah sampel 
yang mewakili populasi yang ada pada daerah penelitian. Daerah penelitian dibagi menjadi 11 kelurahan. Pengambilan sampel dilakukan dengan cara Stratified Proporsional Random Sampling didasarkan atas klasifikasi objek yang ada pada setiap kelurahan. Sampel diambil dengan memperhatikan proporsi jumlah sampel dalam populasi, sehingga seluruh populasi terwakili oleh sampel yang diambil. Titik sampel diambil secara acak (random) didasarkan atas jumlah tiap klasifikasi

Uji ketelitian hasil interpretasi dilakukan berkaitan dengan tingkat ketelitian minimal dan validitas data hasil interpretasi. Apabila hasil interpretasi tidak memenuhi batas minimal ketelitian yang ditetapkan, maka hasil interpretasi tidak dapat digunakan untuk pengambil keputusan. Data hasil interpretasi memiliki validitas dan akurasi tinggi, apabila terdapat kesesuaian antara hasil interpretasi dengan hasil cek lapangan. Kesesuaian ini diukur dengan prosentase interpretasi benar dibanding interpretasi salah (omisi dan komisi). Untuk uji ketelitian interpretasi pada penelitian ini dipakai Metode Short yaitu perhitungan Matrik Konfusi. Ketelitian yang disyaratkan adalah $>84 \%$ dan kesalahan komisi <20\%. (Sutanto,1994:116)

Hasil perhitungan matrik konfusi pada penelitian dapat dilihat pada Lampiran 2 Tabel 2. Dari Tabel 2 dapat diketahui bahwa prosentase ketelitian antara $66,67 \%$ sampai $100 \%$ dan ketelitian interpretasi secara keseluruhan sebesar 89, 54\%. Ratarata kesalahan komisi sebesar 10, 46\%. Hasil tersebut menunjukkan bahwa secara keseluruhan hasil interpretasi objek pajak dapat diterima karena memenuhi persyaratan batas minimal ketelitian interpretasi data penginderaan jauh.

Identifikasi objek melalui interpretasi Citra Ikonos diperoleh data objek Pajak Bumi dan Bangunan. Identifikasi objek dilakukan di setiap kelurahan di Kecamatan Jebres. Melalui identifikasi tersebut dapat diketahui sebaran objek pajak di setiap kelurahan.
Setelah proses identifikasi selesai, maka dari hasil interpretasi Citra Ikonos dapat diperoleh peta tematik yang mencakup keseluruhan hasil interpretasi. Untuk memudahkan analisis, maka pemetaan dilakukan perkelurahan. Pemetaan objek pajak bumi dan bangunan menggunakan skala yang berbedabeda pada masing-masing kelurahan, hal ini dilakukan karena luas wilayah yang dipetakan berbeda - beda, sehingga agar dapat menampilkan objek pajak bumi dan bangunan yang dipetakan, maka skala peta disesuaikan dengan luas wilayah masing masing kelurahan.

Setelah identifikasi obyek pajak melalui interpretasi citra Ikonos selesai dilakukan, maka proses selanjutnya adalah melakukan evaluasi peta Blok PBB melalui analisis overlay. Peta yang akan dioverlay adalah peta Blok PBB dan peta hasil interpretasi citra Ikonos. Selisish obyek hasil overlay ditunjukkan pada Tabel 3 berikut ini:

Tabel 3.

Perbedaan Jumlah Objek Pajak Hasil Overlay

Peta Blok dan Hasil Interpretasi Citra Ikonos

\begin{tabular}{|l|l|l|l|l|}
\hline No & $\begin{array}{c}\text { Peta Hasil } \\
\text { Interpretasi }\end{array}$ & $\begin{array}{c}\text { Peta } \\
\text { Blok } \\
\text { PBB }\end{array}$ & $\begin{array}{c}\text { Hasil } \\
\text { Overlay }\end{array}$ & Obyek \\
\hline 1 & 59 & 20 & 39 & Rumah \\
\hline 2 & 23 & 9 & 14 & $\begin{array}{l}\text { Pabrik } \\
\text { dan } \\
\text { rumah }\end{array}$ \\
\hline 3 & 7 & 3 & 4 & $\begin{array}{l}\text { Pabrik } \\
\text { dan } \\
\text { rumah }\end{array}$ \\
\hline 4 & 84 & 72 & 12 & $\begin{array}{l}\text { Rumah } \\
\text { dan } \\
\text { pertokoan }\end{array}$ \\
\hline 5 & 6 & 5 & 1 & Pabrik \\
\hline 6 & 99 & 3 & 96 & Rumah \\
\hline 7 & 94 & 0 & 94 & Rumah \\
\hline 8 & 6 & 0 & 6 & Rumah \\
\hline 9 & 15 & 12 & 3 & $\begin{array}{l}\text { Pabrik } \\
\text { dan } \\
\text { rumah }\end{array}$ \\
\hline Jml & 393 & 124 & 269 & \\
\hline
\end{tabular}

Melalui Tabel 3 dapat diketahui bahwa hasil overlay antara peta blok PBB dan hasil interpretasi Citra Ikonos terdapat perbedaan jumlah objek pajak. Selisih objek 
hasil overlay kedua peta tersebut adalah 269 objek yang terdiri dari berbagai macam objek PBB antara lain rumah, pabrik dan pertokoan. Dengan demikian maka peta Blok PBB dapat dievaluasi menggunakan hasil interpretasi Citra Ikonos.Berdasarkan hasil penelitian yang telah dilakukan dapat ditarik kesimpulan bahwa Citra Ikonos dapat digunakan sebagai sumber data utama untuk pendataan objek Pajak Bumi dan Bangunan.

\section{SIMPULAN}

Berdasarkan hasil analisis data dan pembahasan yang telah dikemukakan dapat disimpulkan sebagai berikut:

1. Tingkat ketelitian interpretasi Citra Ikonos untuk pendataan objek Pajak Bumi dan Bangunan adalah 89, 54\% dan kesalahan komisi adalah 10, 46\%. Dengan demikian keseluruhan hasil interpretasi Citra Ikonos dapat diterima karena telah memenuhi persyaratan batas minimal ketelitian interpretasi data penginderaan jauh.

2. Pemetaan objek Pajak Bumi dan Bangunan berdasarkan hasil Interpretasi Citra Ikonos menghasilkan 11 peta objek Pajak Bumi dan Bangunan tingkat kelurahan, dan 1 peta sebaran objek Pajak Bumi dan Bangunan yang belum didata di Peta Blok PBB.

3. Hasil evaluasi Peta Blok PBB menggunakan hasil interpretasi Citra Ikonos terdapat 269 objek pajak yang belum terdata pada peta blok PBB. Dengan demikian terbukti bahwa Citra Ikonos dapat digunakan sebagai sumber data utama untuk pendataan objek pajak bumi dan bangunan.

\section{DAFTAR PUSTAKA}

Leksono, Bambang Edhi, dan Yuliana Sulilowati, 2008, The Accuracy Improvement of Spasial Data For Land
Parcel and Building Taxation Object by Using The Large Scale Ortho Image Datam, Bandung: Institut Tegnologi Bandung.

Pramadani, Yasa, 2004, Pemanfaatan Citra Satelit Ikonos dan Sistem Informasi Geografi untuk Mengetahui Nilai Jual Objek Pajak Bumi di Kecamatan Danurejan Kota Yogyakarta, Skripsi, Yogyakarta: Fakultas Geografi. Universitas Gadjah Mada.

Purwadhi, F. Sri Hardiyanti, 2001, Intepretasi Citra Digital, Jakarta: Grafindo.

Santosa, Birowo Budhi, 1987, Penggunaan Foto Udara Untuk Memetakan Obyek Pajak Bumi dan Bangunan di Kotamadya Yogyakarta, Skripsi, Yogyakarta: Fakultas Geofrafi. Universitas Gadjah Mada.

Short, M. Nicholas, 1982, The Landsat Tutorial Workbook, Washington: Scientific and Technical Information Branch.

Simarangkir, Saraswaty, 2005, Pemanfaatan Citra Ikonos dalam Kegiatan Peningkatan Potensi Penerimaan Pajak Bumi dan Bangunan, Studi Kasus: Kelurahan Sukaresmi pada Kecamatan Tanah Sareal Kota Bogor, Tesis . Bandung: Departemen Teknik Geodesi, Institut Tegnologi Bandung.

Sutanto, 1994, Penginderaan Jauh Jilid I, cetakan 1, Yogyakarta: Gadjah Mada University Press.

1994, Penginderaan Jauh Jilid II, cetakan 1, Yogyakarta: Gadjah Mada University Press.

Spaceimaging, 2003, Ikonos Geometric Accuracy dalam http://www. spaceimaging.com/aboutus / satellites/IKONOS/spectral.htm, diakses tanggal 5 November 2008. 